\title{
THE SAGgING ROPE SIGN IN PERTHES' DISEASE AND ALLIED DISORDERS
}

\author{
A. GRAHAM APLEY, S. WIENTROUB \\ From St Thomas' Hospital, London, \\ The Rowley Bristow Hospital, Pyrford, \\ and The Hospital for Sick Children, Great Ormond Street, London
}

\begin{abstract}
The sagging rope sign is the term used to describe the radiographic appearances which sometimes occur after Perthes' disease. It is seen in severe examples of that disease and indicates damage to the growth plate with a marked metaphysial reaction. The same appearance follows severe epiphysitis after forcible reduction of a congenitally dislocated hip, and certain rare epiphysial dysplasias. The origin and significance of the sign are discussed.
\end{abstract}

George Perkins once remarked that the radiographs of some adults, known to have had Perthes' disease, showed an opaque line in the femoral neck. Its

fancied resemblance to a loosely held rope suggested the name for a sign.

One of us (AGA) noted this observation and has

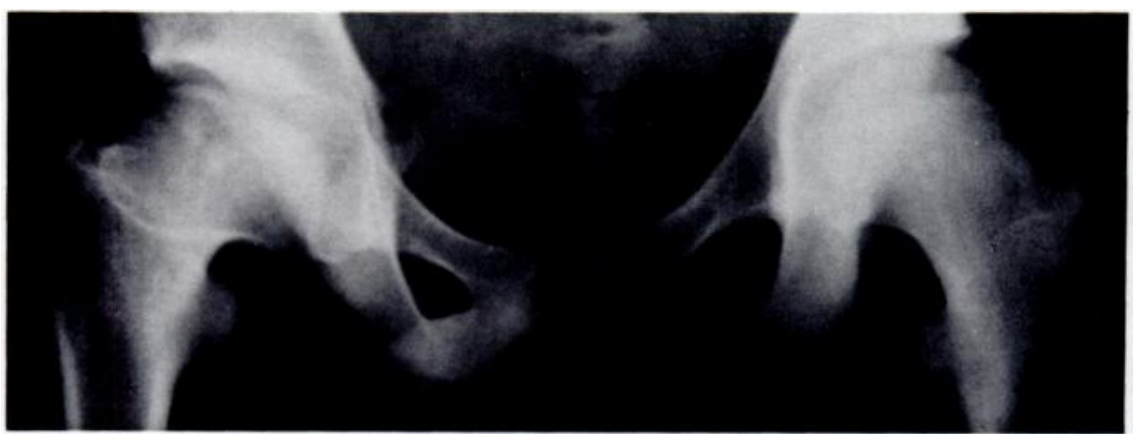

Fig. 1

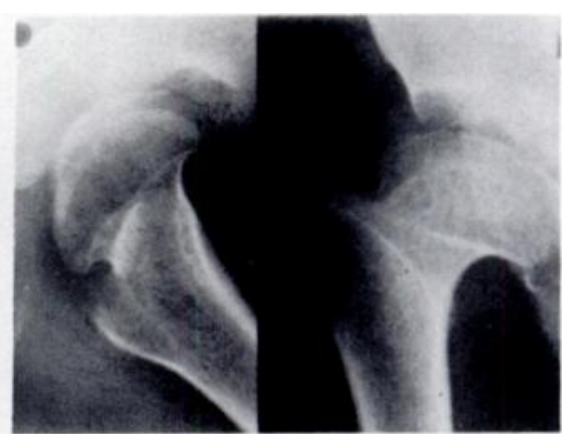

Fig. 2

Figure 1 -Typical appearance of the sagging rope sign. Figure 2-Occasionally the line is almost straight.

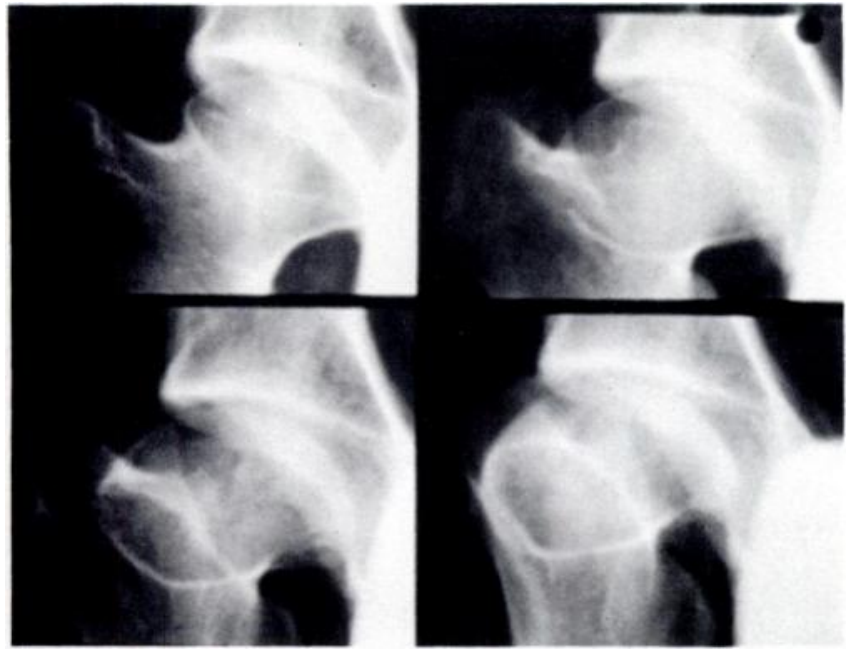

Fig. 3

The top left is in full medial rotation, its neighbour in neutral position; the lower left is half rotated and the lower right fully rotated laterally. since then been collecting representative examples of the sagging rope sign. The other author (SW) was also interested in the sign, not only in Perthes' disease but also in certain cases of congenital dislocation of the hip; he suggested collaboration in drawing attention to it. We now jointly present our observations.

\section{THE SAGGING ROPE SIGN}

The sign consists simply of a thin opaque line in the upper femoral metaphysis. In the anteroposterior view (Fig. 1) it extends laterally from the inferior border of the neck for a variable distance, frequently reaching the superior border; usually the line is curved, sagging at its centre, but occasionally it is almost straight (Fig. 2). It is seen equally well in the lateral view. The appearance varies considerably when the hip is rotated, but the line is always completely contained within the neck (Fig. 3 ).

A visible sagging rope sign in Perthes' disease seems

A. G. Apley, FRCS, Singleton Lodge, West Byfleet, Surrey, England.

S. Wientroub, MD, Department of Orthopaedic Surgery and Traumatology, Ichilov Hospital, Tel-Aviv University, Tel-Aviv, Israel. Requests for reprints should be sent to Mr A. G. Apley. 

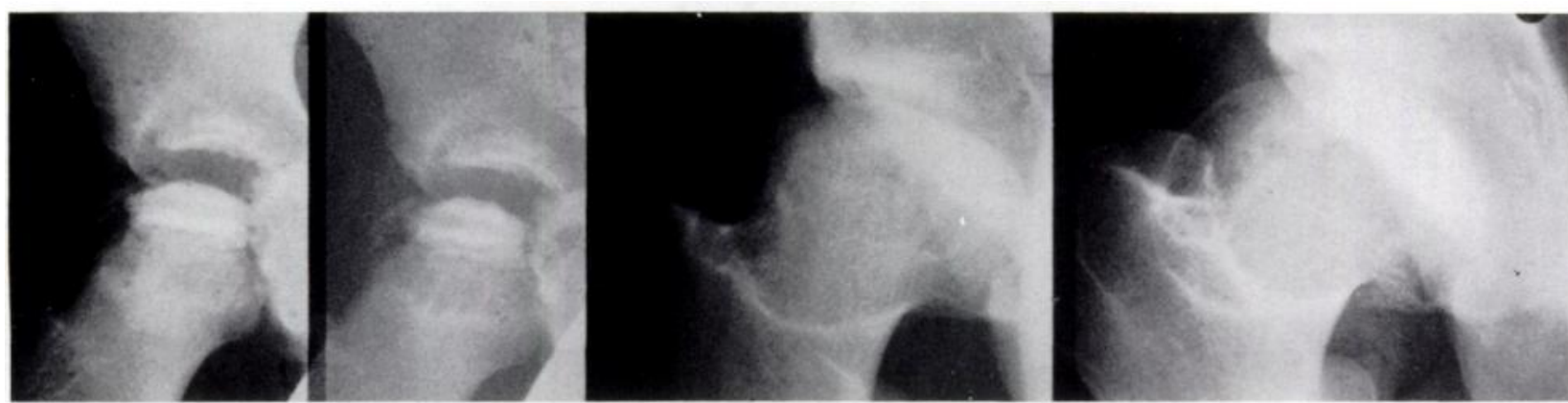

Fig. 4

The chronological sequence of radiographs in this patient strongly suggests that the line is derived from the distal edge of the band of metaphysial rarefaction.

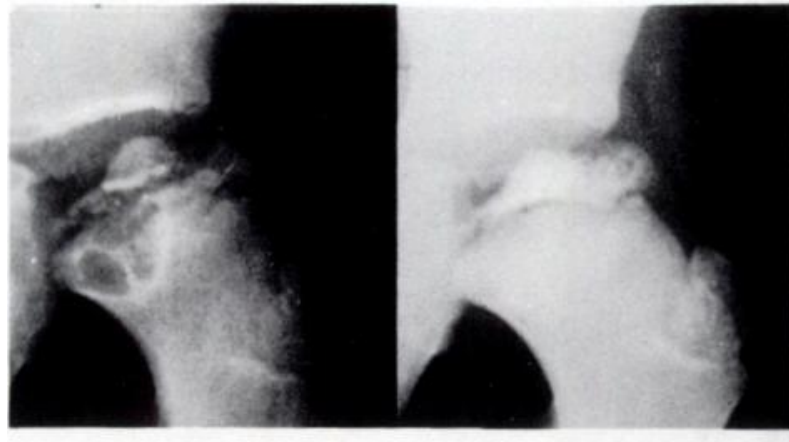

Fig. 5

This sequence suggests that the line is derived from the edge of a metaphysial cyst.
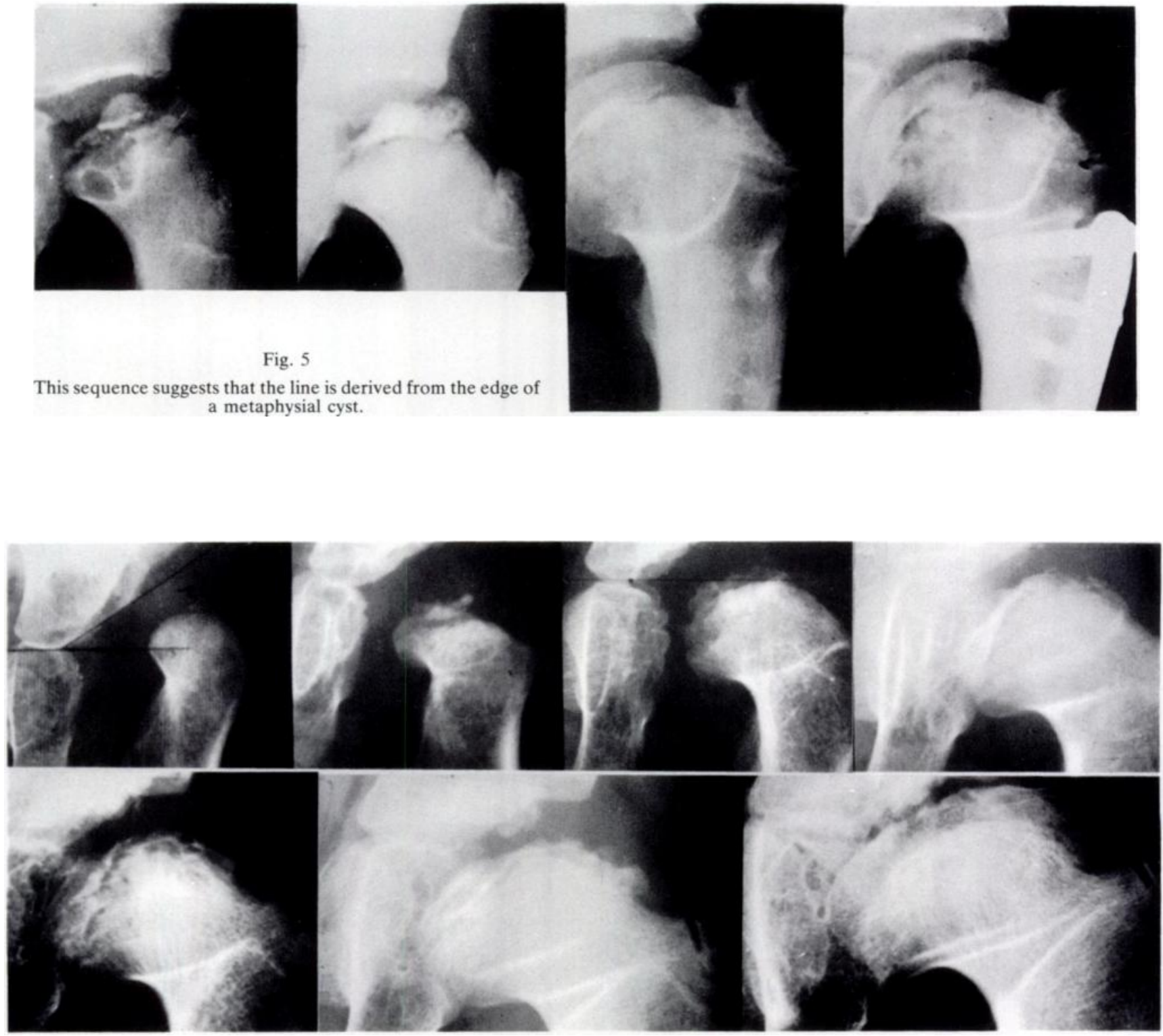

Fig. 6

This patient's congenital dislocation was treated by forceful manipulation under anaesthesia; the top row shows development of epiphysitis followed by a sagging rope sign. The hip was then examined under anaesthesia, apparently with sufficient force to cause a second ischaemic incident leading to a second "sagging rope". 
always to be associated with one or more of the following abnormal features: a short, thick femoral neck; a flat capital epiphysis; premature closure of the growth plate; and sometimes an overgrown greater trochanter. These features are consistent with severe damage to the capital epiphysis and to the growth plate, with temporary or permanent arrest of growth (Edgren 1965). The sign is in fact found only when the epiphysial disorder is associated with changes in the growth plate and the adjacent metaphysis. It seems that the germinal cells, which are nourished from the epiphysial side, become inactive. In addition metaphysial vessels may, in the process of revascularising the ischaemic epiphysis, cross the growth plate and thereby complete the premature closure (Lloyd-Roberts and Ratliff 1978).

The line seems to have its origin in the distal edge of the band of rarefaction in the metaphysis (Fig. 4), and this band is of course associated with epiphysial ischaemia severe enough to damage the growth plate. It is first seen as healing occurs and the metaphysis recalcifies, appearing, as one might expect, at the junction of normal bone and rarefied metaphysis. In some instances it seems to develop from the distal edge of a metaphysial cyst (Fig. 5). Its length is almost certainly related to the extent of the ischaemic damage, or at least to the extent of the metaphysial response to that damage. As growth proceeds the line "migrates" distally and its appearance is reminiscent of a Harris' line, to which it is analogous in that it appears after the inhibition and subsequent recovery of growth.

\section{SIGNIFICANCE OF THE SIGN}

The sagging rope sign is not found exclusively in Perthes' disease. It is seen also in the analogous condition, so-called epiphysitis (avascular necrosis), which may follow treatment of a congenitally dislocated hip, though only when the epiphysitis is severe. Figure 6 strongly suggests that two separate incidents of ischaemia may lead to a double rope sign. Figure 7 provides a typical

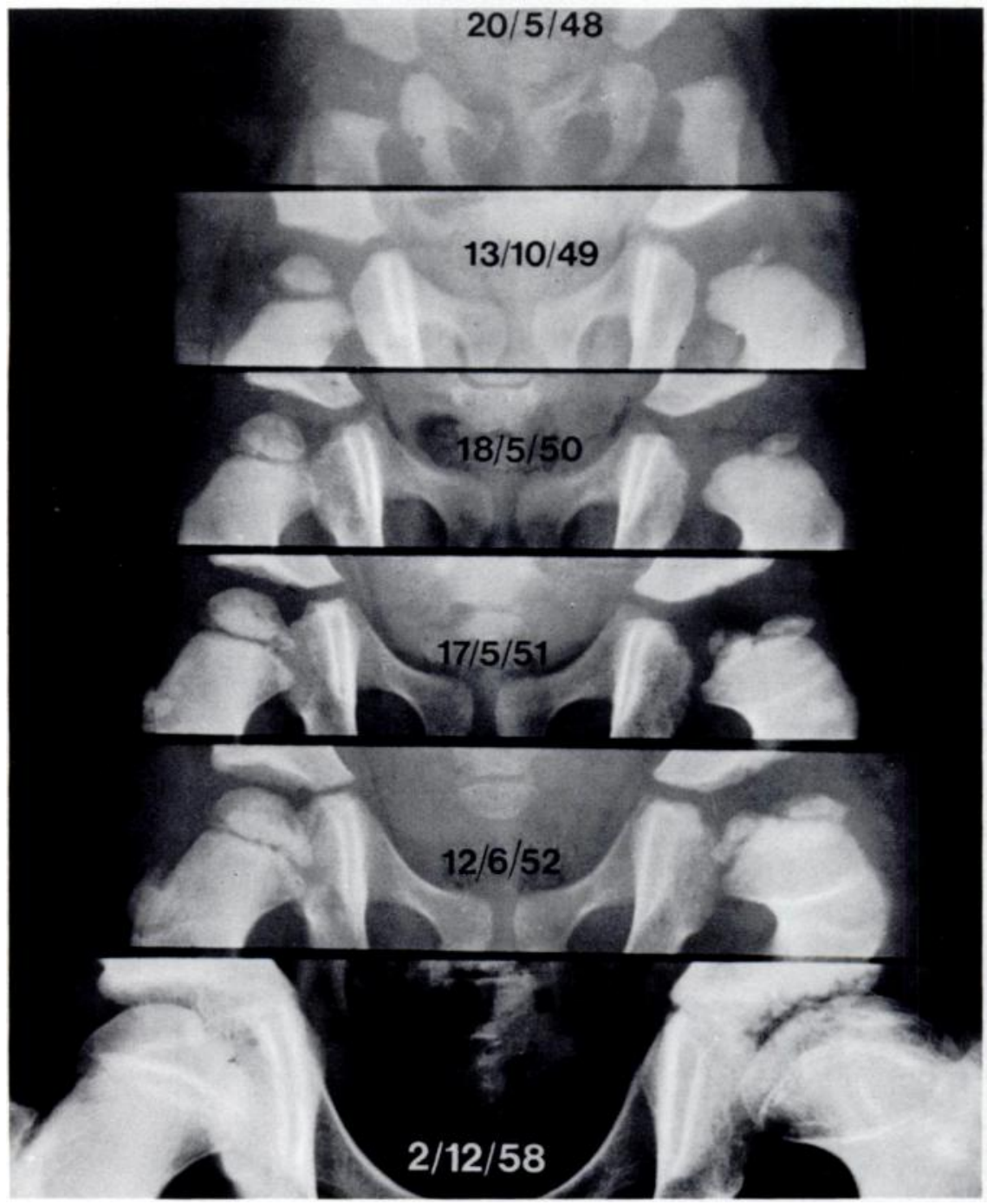

Fig. 7

Reduction of this congenitally dislocated hip has been followed by severe ischaemic changes and a typical sagging rope sign has developed. 


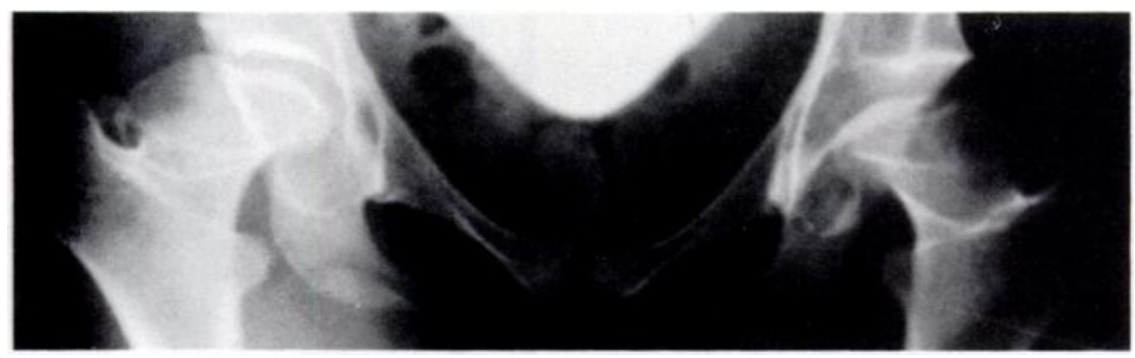

Fig. 8

This patient had relatively mild multiple epiphysial dysplasia, and sagging rope signs have developed.

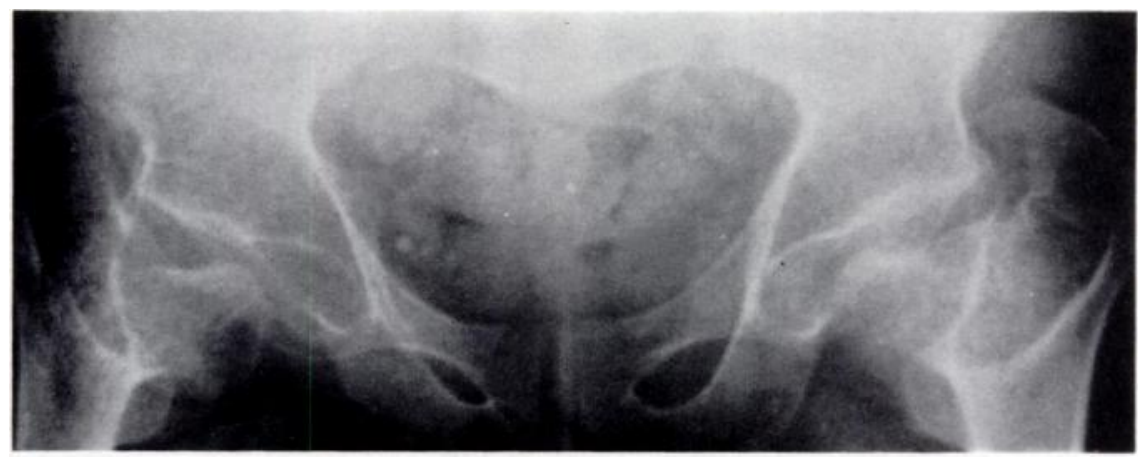

Fig. 9

The hips of this patient with spondylo-epiphysial dysplasia were severely affected; the line is more curved than usual.

(single rope) example of congenital dislocation leading to epiphysitis.

A few other conditions, distinctly uncommon, but with a comparable pathology also may show the sign. They include multiple epiphysial dysplasia (Fig. 8), spondylo-epiphysial dysplasia (Fig. 9) and cretinism. In achondroplasia and hypochondroplasia a line similar to the sagging rope is sometimes seen, presumably as a consequence of the abnormality of the growth plate; in both these disorders, however, the changes are confined to the metaphysis (Ponseti 1970) so that the head does

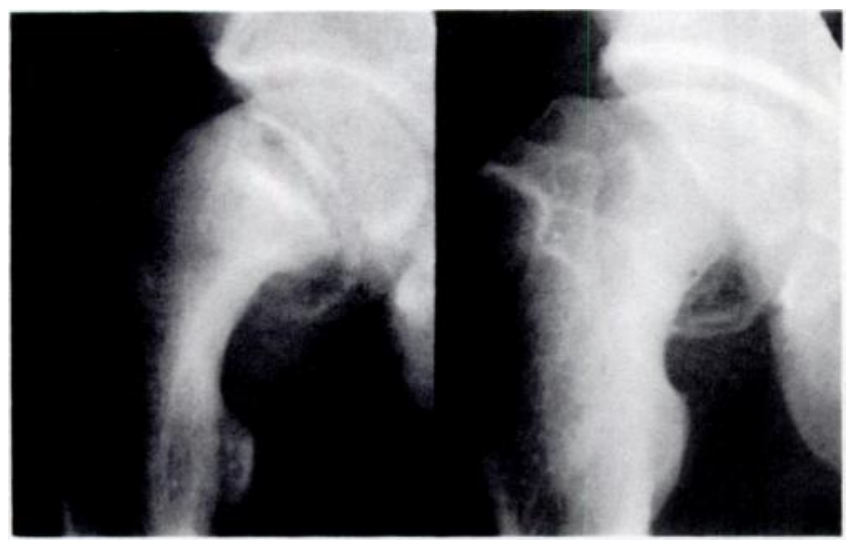

Fig. 10

This slipped upper femoral epiphysis was never reduced. As usual there are various lines visible in the neck, but they in no way resemble the sagging rope sign. not become flattened. These diseases are all rare and they all have other distinctive features.

It might be supposed that the sign would develop as the sequel to adolescent coxa vara, but this is not so (Fig. 10) for the displaced epiphysis is itself normal and the metaphysial changes are not the result of any disease but merely the consequence of "traumatic loosening and

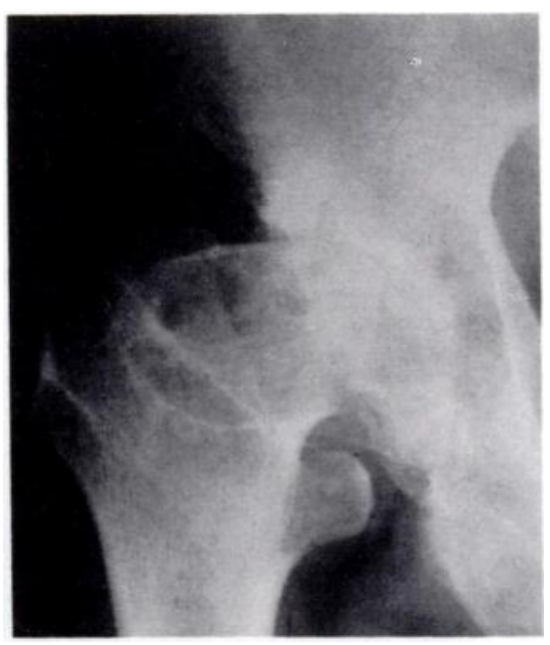

Fig. 11

This man could recall no symptoms of hip disorder in childhood, but there is a wellmarked sagging rope sign. It is suggested that he had probably had Perthes' disease, but that he was too tough or his symptoms too mild for medical advice to be sought. 
displacement" (Aegerter and Kirkpatrick 1975). So that, in practice, unless the patient has had treatment for a congenitally dislocated hip, the sagging rope sign nearly always implies that he has had Perthes' disease. Moreover, he has had it in a severe form, for, as might be expected from its origin, the sign is not seen after the milder varieties of Perthes' disease, in which neither the growth plate nor the metaphysis is affected (Catterall 1971).

It is clear therefore that, in Perthes' disease, the presence of a sagging rope sign has considerable prognostic significance: the disease has been severe, and the growth plate damaged. These features, in turn, have an important implication regarding treatment. The surgeon is alerted to the possibility of progressive shortening and varus deformity of the neck, as well as gluteal insufficiency due to trochanteric overgrowth; he may consequently wish to consider trochanteric epiphyseodesis before secondary deformity becomes established.

The sagging rope sign is valuable also when studying the natural history of Perthes' disease, and in deriving statistics. Thus it would be useful to know how many children suffer from Perthes' disease, and how many osteoarthritic hips are secondary to it. The difficulty is that some affected children have no symptoms, and in them the secondary nature of any subsequent osteoarthritis may be unrecognised. Figure 11 illustrates this point: despite the fact that this man gave no appropriate history, the sagging rope sign strongly suggests that his degeneration is secondary to Perthes' disease.

A sign which has diagnostic, prognostic and possibly statistical significance seems worth recording.

We are grateful to Mr G. C. Lloyd-Roberts for access to his collection and for his helpful advice. Dr S. Wientroub was supported by a grant from the Lewis Fellowship Fund, London.

\section{REFERENCES}

Aegerter EE, Kirkpatrick JA Jr. Orthopaedic diseases_physiology_pathology_radiology. 4th ed. Philadelphia: WB Saunders Company, 1975:420-4.

Catterall A. The natural history of Perthes' disease. J Bone Joint Surg [Br] 1971;53-B:37-53.

Edgren W. Coxa plana: a clinical and radiological investigation with particular reference to the importance of the metaphyseal changes for the final shape of the proximal part of the femur. Acta Orthop Scand 1965;Suppl 84.

Lloyd-Roberts GC, Ratlif AHC. Perthes' disease. Part I: Pathogenesis classification and treatment. In: Hip disorders in children. London: Butterworths, 1978:119-49.

Ponseti IV. Skeletal growth in achondroplasia. J Bone Joint Surg [Am] 1970;52-A:701-16. 